\title{
Clinical Profile and Outcome of Infective Endocarditis in a Tertiary Care Centre: Retrospective Study
}

\author{
Tirumala Naresh $A^{1}$, Rajasekhar $D^{1^{*}}$, Vanajakshamma $\mathbf{V}^{1}$, Sreedhar Naik $\mathrm{K}^{1}$, Abha Chandra ${ }^{2}$ and Abhijit \\ Chaudhury ${ }^{3}$
}

${ }^{1}$ Department of Cardiology, SVIMS, India

${ }^{5}$ Department of Cardiothoracic and Vascular Surgery, SVIMS, India

${ }^{6}$ Department of Microbiology, SVIMS, India

Submission: March 19, 2017; Published: May 08, 2017

*Corresponding author: D Rajasekhar, Professor and Head, Department of Cardiology, SVIMS, Tirupati-517507, AP, India, Tel: +91-9849221650; Email: cardiologysvims@gmail.com

\section{Abstract}

Objective: This study was conducted to outline the clinical profile and outcomes of infective endocarditic (IE). It provides a contemporary picture of the presentation, etiology and outcomes of IE.

Methods: A total of 97 consecutive cases of definitive IE who met the modified Duke's definitive criteria were included in the study. We analysed their clinic-epidemiologic features and outcomes.

Results: The mean age was $34.8 \pm 14.6$ years with male preponderance $(57.7 \%)$. Rheumatic heart disease (RHD) (29.8\%) was the commonest underlying cause followed by congenital heart disease (CHD) (20.6\%). Fever as the main clinical feature was seen in $95.8 \%$. About $61.8 \%$ of patients were in New York Heart Association (NYHA) class II. Blood culture was positive in $44.3 \%$ with commonest organisms being Staphylococcus aureus $(10.3 \%)$ and Streptococci viridians (9.3\%). Most common valve involvement was mitral valve (50.5\%) followed by aortic valve (38.14\%). Eleven (11.33\%) patients had right-sided cardiac valve involvement. Complications were cardiovascular in 27 (27.8\%) cases congestive heart failure in $24.7 \%$, atrioventricular block in (3.1\%), renal failure in 5 cases (5.2\%) and neurological in $10(10.30 \%)$ cases. In-hospital mortality was high (34.1\%). Only 17 (17.5\%) patients underwent surgery for IE.

Conclusion: Morbidity as well as mortality is considerably high with IE. Staphylococcal infection is the most common etiologic agent RHD is the commonest underlying heart disease in our population. Culture positivity rates and surgery for infective endocarditis is low. Early cardiac surgery may help to improve the outcomes in these patients.

Keywords: Infective endocarditic; Rheumatic heart disease; Congenital heart disease

\section{Introduction}

Infective endocarditis (IE) is a disease characterized by high morbidity and mortality. Despite advances during the past century in diagnosis [1,2], medical therapy [3] and surgical treatment [4]. Mortality rates have not changed substantially in the past 25 years. The current in-hospital mortality rate for patients with IE is $15 \%$ to $20 \%$, with1year mortality approaching $40 \%$ [5]. Majority of patients in our clinical practice do not manifest all the classical signs of endocarditis. Thus, a high index of clinical suspicion and early investigation of those at risk is required. Echocardiography remains central to the diagnosis of IE. The common differential diagnosis in our patients includes nodules due to acute rheumatic fever, ruptured chordae, myxomatous degeneration, and thrombus. Other causes of vegetation-like structures include neoplasia (atrial myxoma, marantic endocarditis, papillary fibro elastoma, and carcinoid), auto immune diseases (systemic lupus erythematosus, Wegener's granulomatosis, Behçet's disease, and eosinophilic heart disease) and even normal structures like Chiari malformation, and Lambl's excrescences. The sensitivity of transthoracic-echocardiography (TTE) is reported to be $40-63 \%$ [5]. The recent ACC guidelines [6] recommend the use of modified Dukes criteria as the primary scheme for the diagnosis of IE (Figure 1). 


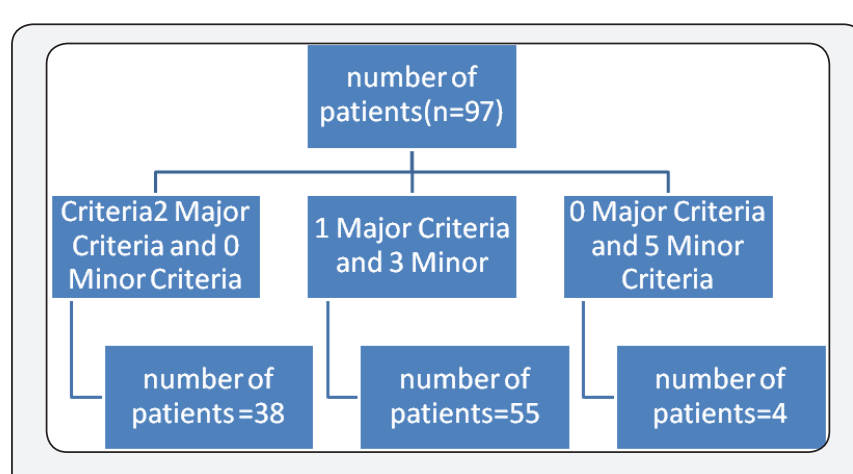

Figure 1: Dukes criteria category.

\section{Aims and Objectives}

This study aims to outline the clinical profile and outcome of infective endocarditis. It provides a contemporary picture of the presentation, etiology, and outcome of infective endocarditis (IE).

\section{Materials and Methods}

This is a retrospective observational study consisting of a total of 97 consecutive cases of definitive infective endocarditis (IE), admitted between January 2008 and May 2016, at Sri Venkateswara Institute of Medical Sciences (SVIMS), Tirupati, India. Patients who met the modified Duke's definitive criteria [7] for IE were included in this study. We analysed patients clinic-epidemiologic features and outcomes. The data regarding the clinical presentation, predisposing factors, precipitating cause, investigative work up and outcome were recorded.

\section{Inclusion Criteria}

All age groups of patients diagnosed as definitive infective endocarditis based on modified Dukes criteria were included.

\section{Exclusion Criteria}

Patients who did not meet Dukes criteria, patients unwilling to participate and no evidence of IE at surgery were excluded from study.

\section{Echocardiographic Study}

Transthoracic Echocardiography (TTE): All patients underwent TTE. Two dimensional and Doppler echo cardio graphic studies were performed in the left lateral decubitus position with conventional views (parasternal long, short axis and apical 4 chamber view) according to the American Society of Echocardiography guidelines [8]. Echocardiogram with oscillating intra cardiac mass on valve, sub valvular structures, site of impact of regurgitate jets, or on prosthetic material without another alternatively anatomical explanation were considered positive for IE. Other important echo cardio graphic features which were considered positive for IE are abscess, new prosthetic valve dehiscence or valvular regurgitation.

\section{Blood Cultures}

At least three blood culture samples (aerobic and anaerobic) were obtained before initiation of antibiotic therapy. Blood samples were drawn from different puncture sites (three samples) separated apart by at least one hour if warranted clinically, fungal cultures were also done.

\section{Statistical Analysis}

Continuous variables are expressed as mean \pm SD . Categorical variables are presented as frequencies and percentages.

\section{Results}

The mean age of IE patients was $34.8 \pm 14.6$ years, with highest concentration $(23.7 \%)$ in the defined as age group of 31-40 years and with male preponderance (57.7\%). Normal systolic left ventricular function, defined as ejection fraction (EF) $\geq 55 \%$ was seen in 59 cases $(60.8 \%)$. Mild pulmonary arterial hypertension (PAH) was present in 49 cases $(50.51 \%)$. Prior history of IE was found in 4 cases (4.1\%) Most of the cases (95\%) had no prior antibiotic use before admission Fever (95.9\%) was the commonest presenting symptom and physical sign pallor (32.9\%) was the second common physical finding. New York Heart Association (NYHA) Class-II was found in $61.85 \%$ of the study subjects Hypertension (8.2\%) was the most common associated clinical condition. Rheumatic heart disease (RHD) (29.9\%) was the commonest underlying cause followed by congenital heart disease (CHD) (20.6\%) (Table 1). Bicuspid aortic value (55\%) was the most common CHD causing IE. Most common valve involvement was found to be mitral valve (50.5\%) followed by aortic valve (38.1\%). Eleven (11.3\%) patients had right-sided cardiac valve involvement.

Table 1: Predisposing cardiac disease for IE.

\begin{tabular}{|c|c|c|}
\hline $\begin{array}{c}\text { Predisposing Cardiac } \\
\text { Disease }\end{array}$ & $\begin{array}{c}\text { Number of Patients } \\
\text { (n=97) }\end{array}$ & Percentage \\
\hline RHD & 29 & $29.90 \%$ \\
\hline CHD & 20 & $20.60 \%$ \\
\hline MVP & 9 & $9.30 \%$ \\
\hline Degenerative valve & 2 & $2.10 \%$ \\
\hline Prosthetic valve & 19 & $19.60 \%$ \\
\hline Normal valve & 18 & $18.60 \%$ \\
\hline
\end{tabular}

IE: Infective Endocarditis; RHD: Rheumatic Heart Disease; CHD: Congenital Heart Disease; MVP: Mitral Valve Prolapse

Vegetations were present in 93 cases (95.9\%). Mitral regurgitation $(42.3 \%)$ was the most common abnormality found on echocardiography. Single vegetation was found in 83 cases $(89.3 \%)$ and size of $\leq 5 \mathrm{~mm}$ was seen in 61 cases (66.7\%). Perivalvular abscess was seen in 3 cases of whom two had prosthetic valve and one had congenital bicuspid valve. Blood culture was positive in $44.3 \%$ of cases with commonest cultured organisms being Staphylococcus aureus (10.3\%) and 
Streptococci viridians (9.3\%). Negative blood culture was found in 54 cases $(57.7 \%)$ (Table 2). Complications associated with IE were cardiovascular in 27 (27.8\%) cases (congestive heart failure in $24.7 \%$, atrioventricular (AV) block in $3.1 \%$ ), renal failure 5 cases (5.1\%), neurological in 10 cases $(10.3 \%)$ and in-hospital mortality remained high (34.02\%) (Table 3). Congestive heart failure was seen in 24 cases. Of these mitral valve was involved in 6 cases, aortic valve was involved in 3 cases and both mitral and aortic valve were involved in 15 cases. Cerebral embolism was found in 10 cases $(10.3 \%)$, mean size of the vegetation seen in these cases was $12 \pm 3 \mathrm{~mm}$ and were highly mobile with involvement of mitral valve in 6 cases and aortic valve in 4 cases. Peripheral embolism was seen in 5 cases $(5.15 \%)$. AV block was seen in 3 cases of which mitral valve was involved in one case and aortic valve in two cases. Only 17 (17.5\%) patients underwent surgery for IE (Table 4). A total of 80 patients were managed medically out of which 29 died. Most of these cases $(n=18)$ presented in NYHA IV with cardiogenic shock. Mortality with medical management was 29 cases $(36.2 \%)$ while with surgical management was 4 cases (23.5\%).

Table 2: Micro organisms recovered from blood culture of patient with IE.

\begin{tabular}{|c|c|c|}
\hline Micro-organism & $\begin{array}{c}\text { Number of } \\
\text { Patients(n=97) }\end{array}$ & Percentage \\
\hline Steptococci viridans & 9 & $9.30 \%$ \\
\hline Steptococci bovis & 1 & $1.10 \%$ \\
\hline $\begin{array}{c}\text { Staphylococcus } \\
\text { aureus }\end{array}$ & 10 & $10.30 \%$ \\
\hline $\begin{array}{c}\text { Coagulase negative } \\
\text { Streptococci }\end{array}$ & 8 & $8.20 \%$ \\
\hline Pseudomonas & 2 & $2.10 \%$ \\
\hline Enterobacter & 1 & $6.20 \%$ \\
\hline Polymicrobial & 2 & $1.10 \%$ \\
\hline Fungal & 54 & $2.10 \%$ \\
\hline Others & $5.10 \%$ \\
\hline No growth & & $55.70 \%$ \\
\hline
\end{tabular}

IE: Infective Endocarditis

Table 3: Complications and mortality observed in patients with IE.

\begin{tabular}{|c|c|c|}
\hline Complication & Number of Patients & Percentage \\
\hline CHF & 24 & $24.70 \%$ \\
\hline CVA & 10 & $10.30 \%$ \\
\hline AKI & 5 & $5.20 \%$ \\
\hline Thrombocytopenia & 12 & $12.40 \%$ \\
\hline Mortality & 33 & $34.10 \%$ \\
\hline
\end{tabular}

IE: Infective Endocarditis; CHF: Congestive Heart Failure; CVA: Cerebrovascular Accident; AKI: Acute Kidney Injury
Table 4: Management of IE.

\begin{tabular}{|c|c|c|c|}
\hline $\begin{array}{c}\text { Management } \\
\text { strategies }\end{array}$ & $\begin{array}{c}\text { Number of patients } \\
(\mathbf{n = 9 7})\end{array}$ & Percentage & $\begin{array}{c}\text { Mortality } \\
\text { percentage }\end{array}$ \\
\hline $\begin{array}{c}\text { Medical } \\
\text { Management }\end{array}$ & 80 & $82.50 \%$ & $36.20 \%$ \\
\hline $\begin{array}{c}\text { Surgical } \\
\text { Management }\end{array}$ & 17 & $17.50 \%$ & $23.50 \%$ \\
\hline
\end{tabular}

IE: Infective Endocarditis

\section{Discussion}

The current scenario of IE has changed owing to multitude of possible factors which include empirical or indiscriminate use of antibiotics therapy, increasing population of elderly age group, prosthetic devices/pacemaker leads implantation and increasing healthcare acquired infections. The mean age of our patients was 34.8 years and $63.9 \%$ of our patients were younger than 40 years which is very similar to the previous Indian studies [9-11]. The lower mean age is attributable to the fact that, this study also included the paediatric population. Also, RHD which continues to be a rampant problem in the underprivileged population in India predominantly affects younger age group [12].

RHD was the most common underlying heart disease in present study which accounted for $29.9 \%$ of all cases, which is similar to other Indian studies [9]. In rheumatic valavulitis focal nodular thickening of the body and tips of the leaflet is important feature that can be picked up by echocardiogram. Thesenodules are $3-5 \mathrm{~mm}$ in size and have different echogenicity from the valve structures and do not have the characteristic mobility of endocarditic vegetations. These are considered rheumatic verucae equivalents and are seen commonly in the mitral valve; these can be seen on tricuspid and aortic valve also rarely. These verucae need to be differentiated from vegetations of endocarditis.

CHD accounted for $20.6 \%$. This high incidence of CHD in our study is in contrast to a large multi-centric study by Murdoch et al. [12] in which CHD constituted 12\% of IE cases [13]. Bicuspid aortic valve is the most common congenital etiology for infective endocarditis in infants and children. The risk of developing infective endocarditis on a bicuspid aortic valve is $10-30 \%$ over lifetime [14]. In our study, prosthetic valve endocarditis (PVE) constituted 19 (19.6\%) cases of IE which is very similar to other western studies but higher than some previous Indian studies $[9,15,16]$ (Figure 2). Incidence of PVE has increased in India from $1 \%$ in 1980's to $10 \%$ in 1990's [10]. Diagnosis of prosthetic valve endocarditis by the TTE is more difficult because multitude of various imaging artefacts (reverberations, attenuation etc.) can occur with both mechanical and bio prosthetic valves. Particularly in the case of a mechanical valve, TTE may be helpful only when there is large or mobile vegetation or significant regurgitation. These limitations are resolved with the use of transesophageal 
imaging techniques because of the superior imaging quality and posterior transducer position. In contrast to the western data in which mitral valve prolapsed (MVP) was reported to be a common underlying heart lesion, this group constituted $9(9.3 \%)$ patients in our study. Although it is traditionally believed that IE does not affect normal valves, recent large series have reported no underlying structural heart disease in about a third of patients [17]. In our study $18(18.6 \%)$ of patients had no structural heart disease.

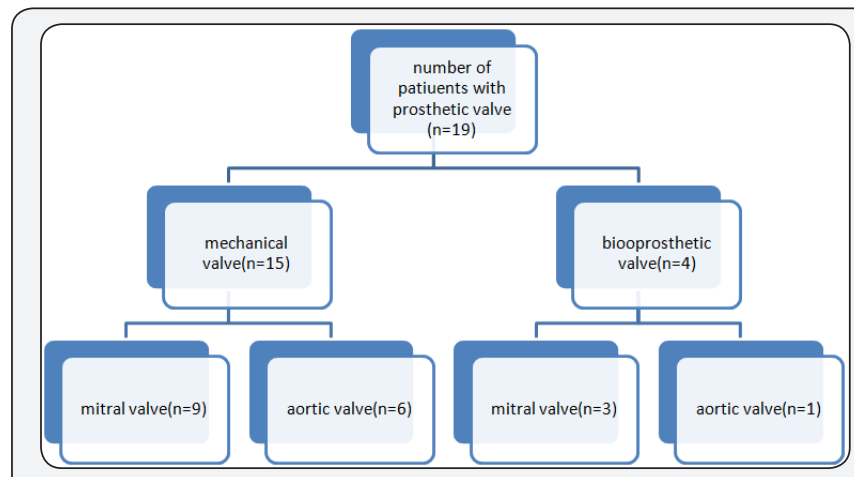

Figure 2: Patients with prosthetic valve endocarditis.

Echocardiography has proved the most important tool in establishing diagnosis of IE in our study. This is especially due to the low culture positivity rates. Vegetations were detected by TTE in 93 (95.9\%). The most common site of vegetations in our study was mitral valve followed by aortic valve which is similar to study by Garg et al. [10] and other Indian studies [9] (Figure 3). A low culture positivity rate noted in our study. Optimal therapy of IE depends on the organism isolated on culture and their sensitivity patterns. This is similar to the study done by Sharad et al. [18]. Ninty three patients had no previous history of antibiotic use. Blood cultures were positive only in 44 cases, this may be because of under reporting of previous antibiotic use [19]. Recent data from the west series has shown therehas been a shift in the microbiological spectrum with Staphylococcus being the commonest isolate [20]. In our study also the most common isolate was Staphylococcus aurous followed by Streptococci viridians. Staphylococcus aureus is now the most common cause of IE in much of the world, according to several recent investigatiors [21]. However, the previous Indian study by Garg et al. [10] had shown Streptococci as the most common isolate. The increasing emergence of Staphylococcus is due to an increasing geriatric population, rising drug abuse, increasing nosocomial infections and use of prosthetic devices. A negative blood culture not only delays the diagnosis, but also misclassifies the patient precluding appropriate antibiotics. IE due to atypical organisms should be considered in negative blood culture cases in immuno compromised, renal failure and patients with impanted prosthetic devices/pacemaker leads and intravenous dwelling catheters [20].

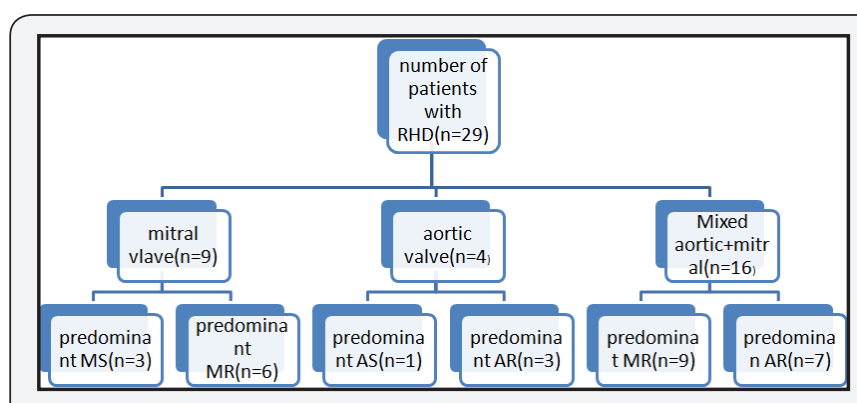

Figure 3: Patients with chronic rheumatic valve diseaseassociated IE.

In our study, the in-hospital mortality was 33 (34.1\%) which is much higher than that reported in the recent studies $(12.6 \%-17.7 \%)[13,22]$. This may have occurred probably due to the complicated and refractory group of patients referred to our centre. Further contributing was delayed presentation of patients to the hospital. Also high culture negative rates and lower rates of surgery 17 (17.5\%) may be contributory.

\section{Limitations}

This is single centre retrospective study. Small sample size. Only in hospital outcomes were taken in the study and long-term follow-up is absent.

\section{Conclusion}

Morbidity as well as mortality is considerably high with IE. Staphylococcal infection is the most common etiologic agent. RHD is the commonest underlying heart disease in our population. Congestive heart failure, renal failure, neurological complications, age and sepsis increase the mortality. The culture positivity rates and surgery for infective endocarditis are low. Early cardiac surgery may help to improve the outcomes in these patients.

\section{References}

1. Osler W (1885) Gulstonian lectures, on malignant endocarditis: lecture I. Lancet 1(3210): 415-418.

2. Durack DT, Lukes AS, Bright DK (1994) Duke Endocarditis Service. New criteria for diagnosis of infective endocarditis: utilization of specific echocardiographic findings: Duke Endocarditis Service. Am J Med 96(3): 200-209.

3. Bayer AS, Bolger AF, Taubert KA, Wilson W, Steckelberg J, et al. (1998) Diagnosis and management of infective endocarditis and its complications. Circulation 98(25): 2936-2948.

4. Middlemost S, Wisenbaugh T, Meyerowitz C, Teeger S, Essop R, et al. (1991) A case for early surgery in native left-sided endocarditis complicated by heart failure: results in 203 patients. J Am Coll Cardiol 18(3): 663-667.

5. Evangelista A, Gonzalez-Alujas MT (2004) Echocardiography in infective endocarditis. Heart 90(6): 614-617.

6. Baddour LM, Wilson WR, Bayer AS, Fowler VG, Bolger AF, et al. (2005) Committee on Rheumatic Fever, Endocarditis, and Kawasaki Disease. Infective endocarditis: diagnosis, antimicrobial therapy, 
and management of complications: a statement for healthcare professionals, council on cardiovascular disease in the young, and the Councils on clinical cardiology, stroke, and cardiovascular surgery and anesthesia, American heart association: endorsed by the infectious diseases society of America. Circulation 111(23): e394-434.

7. Jennifer S, Li Daniel J, Sexton, Nettles R, Fowler VG, et al. (2000) Proposed Modifications to the Duke Criteria for the Diagnosis of Infective. Endocarditis Clin Infect Dis 30(4): 633-638.

8. Henry WL, De Maria A, Gramiak R, King DL, Kisslo JA, et al. (1980) Report of the American Society of Echocardiography Committee on Nomenclature and standards in two-dimensional echocardiography. Circulation 62(2): 212-217.

9. Choudhury R, Grover A, Varma J, Khattri HN, Anand IS, et al. (1992) Active infective endocarditis observed in an Indian hospital 19811991. Am J Cardiol 70(18): 1453-1458.

10. Garg N, Kandpal B, Garg N, Tewari S, Kapoor A, et al. (2005) Characteristics of Infective Endocarditis in a Developing CountryClinical Profile and Outcome in 192 Indian Patients, 1992-2001. International Journal of Cardiology 98(2): 253-260.

11. Math RS, Sharma G, Kothari SS, Kalaivani M, Saxena A, et al. (2011) Prospective Study of Infective Endocarditis from a Developing Country. Am Heart J 162(4): 633-638.

12. Letaief A, Boughzala E, Kaabia N, Ernez S, Abid F, et al. (2007) Epidemiology of Infective Endocarditis in Tunisia: A 10-Year Multicenter Retrospective Study. Int J Infec Dis 11(5): 430-433.

13. Murdoch DR, Corey GR, Hoen B, Miró JM, Fowler VG, et al. (2009) Clinical Presentation, Etiology, and Outcome of Infective Endocarditis in the $21^{\text {st }}$ Century: The International Collaboration on EndocarditisProspective Cohort Study. Arch Intern Med 169(5) 463-473.
14. Brook MM (1999) Perdiatric bacterial endocarditis. Treatment and prophyaxis. Pediatr Clin North Am 46(2): 275-287.

15. Netzer RO, Zollinger E, Seiler C, Cerny A (2000) Infective Endocarditis: Clinical Spectrum, Presentation and Outcome. An Analysis of 212 Cases 1980-1995. Heart 84(1): 25-30.

16. Von Reyn CF, Levy BS, Arbeit RD, Friedland G, Crumpacker CS (1981) Infective Endocarditis: An Analysis Based on Strict Case Definitions. Ann Intern Med 94(4 pt 1): 505-518.

17. van der Meer JT, Thompson J, Valkenburg HA, Michel MF (1992) Epidemiology of Bacterial Endocarditisin The Netherlands. I. Patient Characteristics. Arch Intern Med 152(9): 1863-1868.

18. Sharad R, Jayesh S, Manjunath A, Bhavesh H, Ashwal A, et al. (2014) Clinical Spectrum of Infective Endocarditis in a Tertiary Care Centre in Western India: A Prospective Study. International Journal of Clinical Medicine 5(5): 177-187.

19. Watanakunakorn C, Burkert T (1993) Infective Endocarditis at a Large Community Teaching Hospital, 1980-1990. A Review of 210 Episodes. Medicine 72(2): 90-102.

20. Prendergast BD (2004) Diagnostic criteria and problems in infective endocarditis. Heart 90(6): 611-613.

21. Cabell CH, Jollis JG, Peterson GE, Corey GR, Anderson DJ, et al. (2002) Changing patient characteristics and the effect on mortality in endocarditis. Arch Intern Med 162(1): 90-94.

22. Tornos P, Iung B, Permanyer-Miralda G, Baron G, Delahaye F, et al. (2005) Infective Endocarditisin Europe: Lessons from the Euro Heart Survey. Heart 91(5): 571-575.

\section{Your next submission with Juniper Publishers} will reach you the below assets

- Quality Editorial service

- Swift Peer Review

- Reprints availability

- E-prints Service

- Manuscript Podcast for convenient understanding

- Global attainment for your research

- Manuscript accessibility in different formats

( Pdf, E-pub, Full Text, Audio)

- Unceasing customer service

Track the below URL for one-step submission https://juniperpublishers.com/online-submission.php 